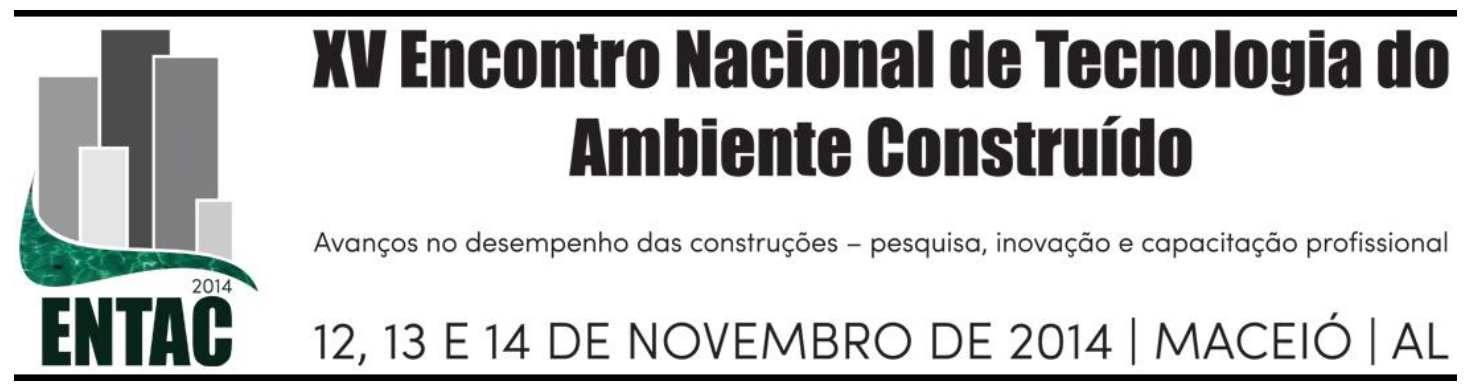

\title{
AVALIANDO O DESEMPENHO DE UMA ROTA ACESSÍVEL NA UFPB
}

COSTA, Angelina Dias Leão (1); SARMENTO, Bruna Ramalho (2);

LAVOR NETO, Edvar Soares de (3); FARIAS, Savina Brito de (4)

(1) UFPB, e-mail: angelinadlcosta@yahoo.com.br; (2)UFRN, e-mail: brunarsarmento@ hotmail.com;

(3) UFPB, e-mail: edvar_soares@ hotmail.com; (4) UFPB, e-mail: savinabr@gmail.com

\begin{abstract}
RESUMO
Diante da necessária adequação das instituições públicas à acessibilidade física, conforme a Lei 10.098 (BRASIL, 2000), e do aumento da quantidade de pessoas com deficiência na comunidade universitária da UFPB, verificou-se a necessidade de implantação de rotas acessíveis no Campus I da Instituição. Inicialmente, foi implantado um Trecho Piloto de Rota Acessível - TPRA no Campus, que liga a Biblioteca Central ao Restaurante Universitário; elaborado pelo Laboratório de Acessibilidade LACESSE. O TPRA possui $273 \mathrm{~m}$ e foi avaliado de forma a realimentar o processo de elaboração dos projetos de acessibilidade. Nesse sentido, realizou-se uma avaliação de desempenho do TPRA a partir da percepção do usuário, diagnosticando de que maneira estes respondem à implantação do percurso acessível; selecionando os pontos positivos e negativos observados pelos mesmos. A avaliação incluiu walkthrough e passeios acompanhados; técnicas importantes para a verificação da funcionalidade do projeto, pois permitiram gerar um rico diagnóstico, com fotos, entrevistas e vídeos; e deixou claro como todos ganharam com a implantação do projeto no que se refere ao tempo de deslocamento, conforto, independência e reconhecimento do espaço. Entretanto, apesar do benefício proporcionado para a orientação e mobilidade do usuário, necessidades de adequação de projeto também foram identificadas, a exemplo do posicionamento centralizado do piso tátil nos passeios, que gerou conflito de fluxo; e da inclinação das rampas, que mesmo com 8\%, conforme dita a NBR 9050/2004 (ABNT, 2004), ainda é desconfortável ao usuário, sendo necessário considerável esforço em sua utilização. A experiência permitiu traçar algumas diretrizes adequando-as às reais necessidades dos usuários, servindo como referência para futuros projetos, já em andamento, que serão aperfeiçoados e questionarão acerca das condições mínimas exigidas pela normativa.
\end{abstract}

Palavras-chave: Rota Acessível, Avaliação, Universidade.

\begin{abstract}
Given the necessary adaptation of public institutions to the physical accessibility, according to Law 10.098 (BRAZIL, 2000), and increased of amount of people with disabilities in the university community at UFPB, there was the need for deployment of accessible routes in Campus I of institution. Initially, we implemented a pilot stretch from Accessible Route - TPRA in the Campus, which connects the Central Library to the University Restaurant; prepared by the Laboratory for Accessibility - LACESSE. The TPRA has 273me and it was assessed to fuel the process of accessible designs. In this sense, the objective was to conduct a performance evaluation TPRA from the user perception, assessing how they respond deploying accessible route; selecting the positive and negative points observed by them. The evaluation included walkthrough and accompanied tours; techniques important to verify the functionality of the design, because allow for generating a rich diagnosis with photos, interviews and videos; and made it clear how all gained with the implementation of the project in relation to the travel time, comfort, independence and recognition of space. However, despite the benefits provided for guidance and user mobility, needs of the project were also identified, such as the central positioning of the tactile floor on the rides, which generated conflict flow; and the slope of ramps, even with $8 \%$, according to NBR 9050/2004 (ABNT, 2004), still causes discomfort to the user, considerable effort is needed in their use. Thus, the experience allowed us to outline some guidelines adapting them to the real needs of users,
\end{abstract}


serving as a reference for future projects. For these reasons, and knowing the urgent need to expand the accessible pedestrian routes, assesses that this study will contribute directly to the improvement of the coming projects, and to warn about the minimum conditions required by the rules.

Keywords: Accessible Route, Evaluation, University.

\section{INTRODUÇÃO}

Além de direito de todo cidadão, conforme a Lei Federal 10.098/00 (BRASIL, 2000), a acessibilidade é uma exigência legal nos projetos de arquitetura, sendo de fundamental importância a adequação de estruturas físicas que promovam o acesso livre e seguro aos usuários, principalmente em instituições públicas, visto que estes espaços atendem a uma maior diversidade de grupos.

Como diretriz fundamental na arquitetura dos espaços, o desenho universal torna-se imprescindível quando se deseja o alcance de ambientes funcionais, "suas áreas de atuação vão desde o desenho de espaços urbanos acessíveis para todos, até o desenho de edifícios e objetos que minimizam as dificuldades para a realização de atividades e aumentam a eficiência de pessoas com deficiência." (DISCHINGER; BINS ELY; PLARDI, 2012).

A acessibilidade se apresenta como a melhor maneira de garantir uma ampla funcionalidade dos projetos; permite uma redução das barreiras de acesso às principais edificações, propondo soluções específicas à orientação espacial de cada grupo de usuários. Baseia-se na possibilidade e condição de alcance, percepção e entendimento para a utilização com segurança e autonomia de edificações, espaço, /mobiliário, equipamento urbano e elementos, como cita a NBR 9050/2004 (ABNT, 2004).

Desse modo, a acessibilidade se mostra como um princípio fundamental a ser seguido no desenvolvimento de projetos, e, em especial, no de rotas acessíveis, que se caracterizam como trajetos contínuos, desobstruídos e sinalizados, conectando ambientes externos ou internos de espaços e edificações (ABNT, 2004). As rotas contribuem com percursos amplamente acessíveis, oferecendo um uso igualitário para os usuários nos trechos em que se aplicam.

O Trecho Piloto de Rota Acessível - TPRA, objeto de estudo deste artigo, foi construído no âmbito do projeto de pesquisa INCLUIR/MEC (COSTA, 2010) e desenvolvido pelo Laboratório de Acessibilidade da UFPB (LACESSE) em 2012. O trecho constitui-se em parte integrante do processo de adequação física do Campus I da Universidade; que vem recebendo um número maior de pessoas com deficiência, advindo da inserção de cotas no processo seletivo de vestibular desde 2011.

O TPRA possui $273 \mathrm{~m}$, faz parte de uma rede de $6 \mathrm{~km}$ de rotas (ainda em processo de projeto), e foi avaliado de forma a realimentar o processo de projetos acessíveis. Encontra-se executado interligando o Restaurante Universitário e a Biblioteca Central. Baseia-se na promoção de estruturas acessíveis de circulação de pedestres que compõem rotas externas e está fundamentado no conceito do desenho universal, a fim de promover a conexão dos principais blocos da Universidade de maneira livre e sem barreiras para todos os usuários, independente de suas limitações. Funciona também como percurso guia para qualquer novo usuário do espaço, já que conecta edifícios importantes e de uso comum a todos da Instituição, e caracteriza-se como uma rota acessível externa que abarca estacionamentos, faixas de travessia de pedestres, calçadas rebaixadas, rampas e sinalização.

Nesse sentido, após 02 anos de sua execução, realizou-se uma avaliação de desempenho do TPRA a partir da percepção do usuário, diagnosticando de que maneira estes 
respondem à implantação do percurso acessível. Este diagnóstico permitiu a seleção dos pontos positivos e negativos observados pelos usuários, além do levantamento de dados que garantiu uma seleção mais humanizada de diretrizes para projetos similares. Salientando a importância da participação do usuário no processo de projeto arquitetônico, que permite observações que vão além das condições mínimas exigidas pelas legislações e normativas, proporcionando decisões projetuais melhor embasadas.

\section{MÉTODO}

Durante a avaliação aprofundaram-se conceitos e técnicas referentes à acessibilidade, destacando os elementos positivos e passíveis de serem melhorados; constatados tanto pelos usuários como pelos pesquisadores ao longo da aplicação das técnicas.

Inicialmente fez-se o walkthrough, que consiste no reconhecimento do objeto de estudo, sem nenhum treino prévio, levantando observações através de fotografias, croquis e gravação de vídeo e áudio (RHEINGANTZ et al, 2009).

Outra técnica utilizada para a avaliação da rota foi o passeio acompanhado (DISCHINGER, 2000), que consiste na avaliação das condições de uso do espaço físico por pessoas com dificuldade de locomoção, seja motora ou visual, nas quais o pesquisador acompanha o usuário e toma nota das impressões obtidas por ambos, bem como, comentários e falas significativas, sem conduzi-lo ou ajuda-lo. Esta técnica gerou um acervo de fotos, entrevistas e gravações, sendo esta última realizada com uma câmera fotográfica (Go Pro) posicionada na cabeça do voluntário, fato que auxiliou no diagnóstico elaborado.

A aplicação das técnicas foi realizada com a cooperação de estudantes e funcionários voluntários do Campus. Ao todo participaram 07 pessoas, dentre as quais havia 03 pessoas com deficiência visual, 01 idoso com mobilidade reduzida, 01 usuária de cadeira de rodas e 02 pessoas sem deficiência; em situações climáticas distintas (dia ensolarado e dia chuvoso).

\section{RESULTADOS E DISCUSSÃO}

\subsection{Walkthrough}

As visitas iniciais ao TPRA mostraram um espaço de intenso fluxo de pedestres e veículos devido à proximidade da Biblioteca Central, do Centro de Convivência e do Restaurante Universitário. De modo geral o ambiente circundante apresenta vegetação arbórea na maior parte da rota, exceto em um trecho próximo à Biblioteca Central, e gramínea ao longo de todo o percurso. A ausência de passeios cobertos dificulta a utilização da rota durante as chuvas.

Quanto ao material utilizado na execução do TPRA observou-se que os pisos táteis são em concreto de cor natural e pintados com tinta "Pinta Piso" azul e amarelo; mesmo passado pouco tempo, essa pintura já apresenta desgaste em diversos pontos, como apresentado nas Figuras 1 e 2, podendo, futuramente, prejudicar a orientação de um usuário com baixa visão, por exemplo, devido à ausência de coloração. Foi ainda identificada a ausência de mapas táteis para orientação no TPRA.

Destaca-se que tal situação se justifica em razão de uma divergência entre fiscalização/execução e projeto executivo; tendo este último primado pela escolha de materiais de boa qualidade e resistência, tomando como referência a dificuldade de manutenção observada na Universidade. Foram especificados pisos em concreto pigmentado, impermeabilizados e resistente às ações das intempéries; além de uma área 
reservada para a instalação de mapa tátil, que contou com um projeto específico, no entanto, este ainda não foi instalado.

Figuras 1 e 2 - Rápido desgaste na pintura do piso tátil.
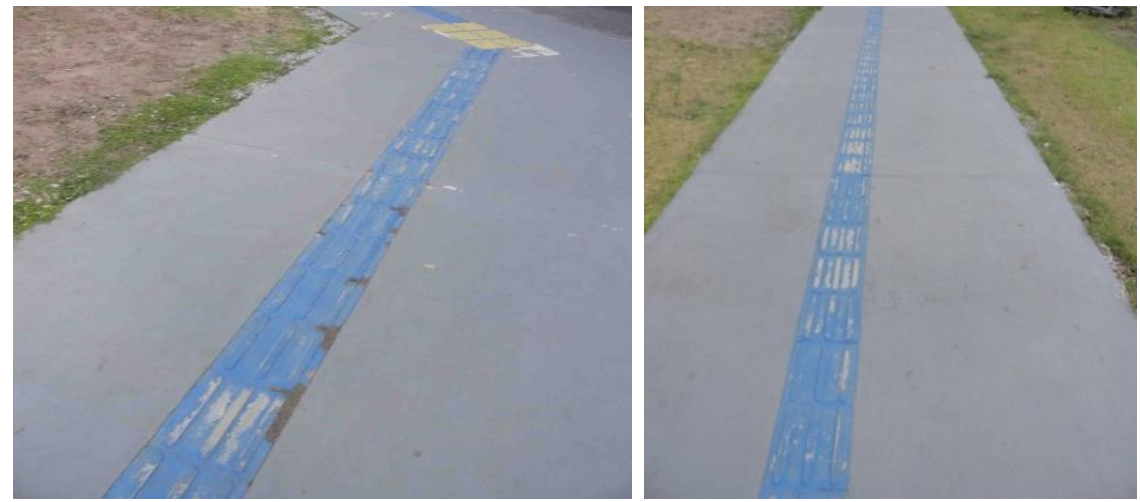

Fonte: Autores. 2013.

Embora não seja o foco deste artigo, vale ressaltar que muitos dos problemas indicados pelos voluntários provêm de falhas na execução do TPRA, o que resultou na ineficiência do trecho em alguns pontos. O projeto executivo determinava, dentre outras questões, a implantação de grelhas nas valas, piso tátil pigmentado e a instalação de mapas táteis nos pontos finais; no entanto, estas recomendações não foram cumpridas, apesar de se tratarem de elementos de fácil aplicação.

\subsection{Passeio Acompanhado}

Diante da realização dos passeios acompanhados foi possível elencar os principais desconfortos relatados por cada voluntário participante, como segue no Quadro 1.

\section{Quadro 1 - Indicação dos problemas observados por cada participante durante a}

\section{realização do passeio acompanhado.}

\begin{tabular}{|c|c|l|}
\hline Voluntário & Condição climática & \multicolumn{1}{c|}{ Dificuldades indicadas pelos usuários } \\
\hline Cadeirante & Dia ensolarado & $\begin{array}{l}\text { Inclinação da rampa causou desconforto; } \\
\text { Sente falta de uma sinalização sonora para travessia de rua. }\end{array}$ \\
\hline $\begin{array}{c}\text { Deficiente } \\
\text { visual 1 }\end{array}$ & Dia ensolarado & $\begin{array}{l}\text { Não conhecia o piso tátil; } \\
\text { Desorientou-se espacialmente na travessia de rua devido à ausência de piso } \\
\text { tátil na faixa elevada; } \\
\text { Sentiu falta de apoios/corrimãos nas rampas; } \\
\text { Sentiu falta de uma sinalização sonora para travessia de rua. }\end{array}$ \\
\hline $\begin{array}{c}\text { Deficiente } \\
\text { visual 2 }\end{array}$ & Dia ensolarado & $\begin{array}{l}\text { Desorientou-se espacialmente na mudança de direção da rota; } \\
\text { Não percebeu o piso tátil de alerta; } \\
\text { Sentiu falta de apoios/corrimãos nas rampas; } \\
\text { Sentiu falta de uma sinalização sonora para travessia de rua. }\end{array}$ \\
\hline $\begin{array}{c}\text { Deficiente } \\
\text { visual 3 }\end{array}$ & Dia ensolarado & $\begin{array}{l}\text { Desorientou-se espacialmente na mudança de direção da rota; } \\
\text { Sentiu falta de apoios/corrimãos nas rampas. }\end{array}$ \\
\hline Idoso & Dia ensolarado & $\begin{array}{l}\text { Sentiu falta de apoios/corrimãos nas rampas; } \\
\text { Reclamou da falta de sinalização para travessia de rua. }\end{array}$ \\
\hline $\begin{array}{c}\text { Pessoa sem } \\
\text { deficiência }\end{array}$ & Dia ensolarado & $\begin{array}{l}\text { Nenhum problema destacado. Percorreu a rota com tranquilidade e } \\
\text { segurança }\end{array}$ \\
\hline
\end{tabular}




\begin{tabular}{|l|c|l|}
\hline $\begin{array}{l}\text { Pessoa sem } \\
\text { deficiência }\end{array}$ & Dia chuvoso & $\begin{array}{l}\text { Apontou alagamento em alguns pontos do trecho, principalmente na rampa } \\
\text { que dá acesso ao estacionamento, o que impossibilitou seu acesso. }\end{array}$ \\
\hline
\end{tabular}

Conforme Quadro 1, observa-se que 04 dos voluntários (cadeirante (Figura 1), deficiente visual 1, deficiente visual 2 (Figura 4), idoso) destacaram a sinalização para travessia de rua um ponto importante para a rota, deixando clara a insegurança apresentada por eles independente de sua dificuldade de locomoção. Quatro voluntários (deficiente visual 1, deficiente visual 2, deficiente visual 3, idoso) destacaram a necessidade de corrimões nas rampas como apoio necessário associado a estas, tal elemento se mostrou essencial para dar mais estabilidade ao usuário. Percebe-se que pessoas com mobilidade reduzida, como os idosos, também exigem apoios fixos em rampas longas para facilitar a locomoção. $\mathrm{O}$ voluntário cadeirante relatou que sente grande dificuldade em percorrer um trecho íngreme por falta de corrimão para apoio e complementou sugerindo sempre utilizar materiais antiderrapantes em rampas, como o utilizado no TPRA.

Outra dificuldade apontada pelo voluntário cadeirante foi a inclinação de uma rampa que, embora esteja de acordo com a NBR 9050/2004 (ABNT, 2004), com inclinação menor que $8,33 \%$, proporcionou certa dificuldade e grande esforço na sua utilização. Isto demonstra que nem sempre as normas atendem completamente o conforto dos usuários.

\section{Figuras 3 e 4 - Voluntária cadeirante e voluntário com deficiência visual}

\section{participando da técnica de passeio acompanhado.}
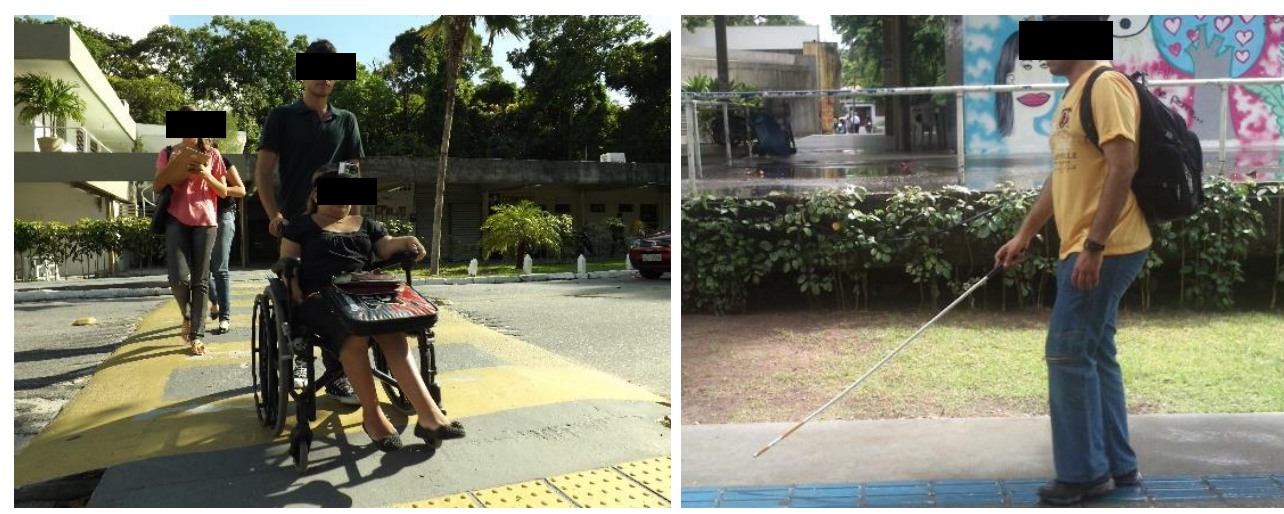

Fonte: Autores, 2013.

Considerando que o voluntário sem deficiência não destacou qualquer observação referente ao trecho, resolveu-se repetir a aplicação da técnica do passeio acompanhado com outro voluntário sem deficiência em um dia chuvoso. Constatou-se que a maior dificuldade era atravessar a faixa de pedestres em uma de suas extremidades, pois, o acúmulo da água pluvial impossibilitava sua passagem dentro do percurso do TPRA, como pode ser observado nas Figuras 5 e 6 . Para isso, recomenda-se a implantação de uma calha (córrego) lateral maior do que a existente, que atenda a demanda de escoamento da água pluvial, evitando o acúmulo de água no local.

Figuras 5 e 6 - Acúmulo de água pluvial próximo à faixa de pedestres elevada e no passeio. 

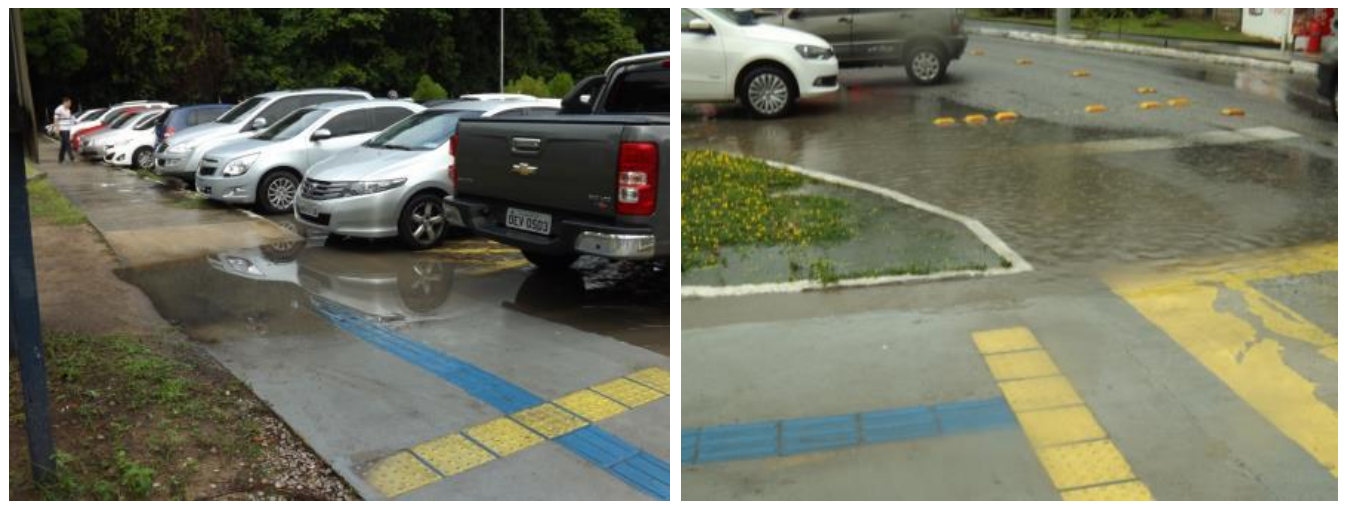

Fonte: Autores, 2013.

Muitos dos voluntários com deficiência visual relataram desconhecerem a funcionalidade do piso tátil e necessitaram de outro ponto de referência, principalmente, quando o percurso mudava de direção. Desse modo, indica-se o investimento em implantação de guias de balizamento e jardins sensoriais, sempre que possível, visto que se caracterizam como elementos de fácil aplicação e baixo custo.

Quando indagado sobre a importância do piso tátil na sua rotina dentro da Universidade um voluntário com deficiência visual destaca outro ponto crítico a ser observado no projeto, que vai além da implantação de pisos táteis: a conscientização dos demais usuários do espaço, visto que foi observada, durante o passeio com este usuário, uma moto estacionada sobre o passeio e um carro ultrapassando a faixa de pedestre enquanto o participante atravessava a rua (Figuras 7 e 8 ).

Figuras 7 e 8 - Moto estacionada sobre o passeio e carro desrespeitando a travessia do pedestre.

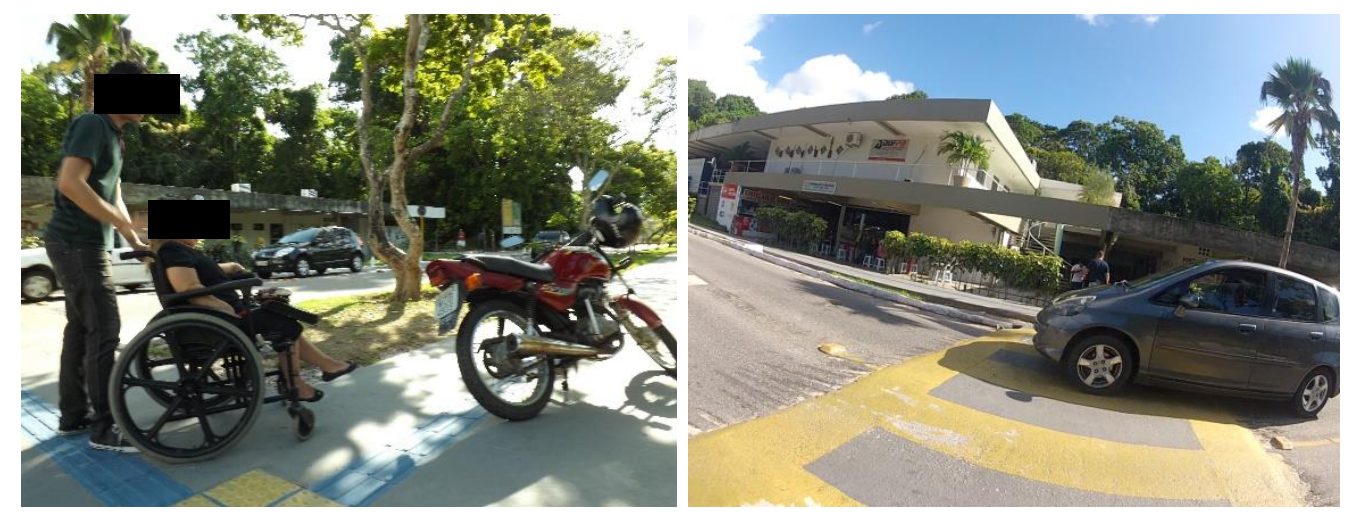

Fonte: Autores, 2013.

A usuária cadeirante comentou que a forma de implantação do piso tátil, no meio do percurso, não atrapalha, pois entende que esta utilização está beneficiando os deficientes visuais. Entretanto, a implantação do piso tátil no eixo central dos passeios com largura de até $2 \mathrm{~m}$ causou conflito no tráfego de pedestres, principalmente, quando usado por uma pessoa com deficiência visual e por uma pessoa cadeirante. O conflito se dá quando o usuário do piso direcional opta se orientar pelo tato, andando sobre ele, causando problemas de fluxo. Recomenda-se, então, locar o piso tátil mais próximo a um dos lados do passeio, de preferência para o lado onde houver alguma guia de 
balizamento natural ou construída, sempre que possível, e implantá-los também sobre as faixas de pedestres elevadas, pois facilitaria a orientação do usuário.

\subsection{Análise Conjunta e Proposição de Diretrizes}

O diagnóstico identificou as barreiras arquitetônicas no percurso e foram discutidas as recomendações necessárias, gerando diretrizes que nortearão o processo de tomada de decisão para futuros projetos de rotas acessíveis.

Buscou-se com um quadro síntese apresentar os resultados obtidos, propondo suas devidas adequações (Quadro 2):

Quadro 2 - Problemas e recomendações para futuros projetos de arquitetura.

\begin{tabular}{|l|l|}
\hline \multicolumn{1}{|c|}{ Problemas encontrados } & $\begin{array}{l}\text { Recomendações propostas pelos usuários e pela } \\
\text { Norma 9050/2004 (ABNT, 2004) }\end{array}$ \\
\hline $\begin{array}{l}\text { Percursos sem guias de referência, além } \\
\text { do piso tátil. }\end{array}$ & Instalar guias de balizamento. \\
\hline Valas sem grelhas. & Instalar grelhas para proteção das valas. \\
\hline Rampas com i= 8,33\%. & Sempre que possível reduzir a inclinação. \\
\hline $\begin{array}{l}\text { Necessidade de apoios/corrimãos nas } \\
\text { rampas. }\end{array}$ & $\begin{array}{l}\text { Projetar apoios/corrimãos em rampas, mesmo nas } \\
\text { mais curtas. }\end{array}$ \\
\hline $\begin{array}{l}\text { Desgaste e descoloração do piso tátil no } \\
\text { passeio. }\end{array}$ & $\begin{array}{l}\text { Implantar piso tátil em material resistente às } \\
\text { intempéries e tingido; } \\
\text { Seguir rigorosamente as especificações do projeto. }\end{array}$ \\
\hline Ausência de piso tátil em faixas elevadas. & Implantar piso tátil nas faixas de pedestres. \\
\hline Ausência de postes sonoros. & Implantar sinalização sonora na travessia de vias. \\
\hline $\begin{array}{l}\text { Posicionamento do piso tátil no meio do } \\
\text { passeio. }\end{array}$ & $\begin{array}{l}\text { Direcionar e implantar o piso tátil para um dos } \\
\text { lados dos passeios, sempre que possível. }\end{array}$ \\
\hline Ausência de mapas táteis. & Instalação dos mapas táteis. \\
\hline
\end{tabular}

Fonte: Autores, 2013.

Desse modo, elencam-se as seguintes diretrizes gerais:

- Consultar o usuário, em especial a pessoa com deficiência, durante a elaboração de projetos acessíveis;

- Elaborar um projeto abrangente, que não priorize um usuário ou uma deficiência específica;

- Especificar materiais resistentes e duráveis para um melhor desempenho e menor custo ao longo dos anos;

- Avaliar o desempenho do ambiente construído de forma contínua, como forma de retroalimentar o processo de projeto.

\section{CONSIDERAÇÕES FINAIS}

Partindo desse contexto, percebe-se que a arquitetura possui recursos de fácil aplicação, que contribuem para a acessibilidade do ambiente construído, promovendo uma percepção do espaço legível que se reflete na apropriação do espaço pelos usuários com segurança e autonomia, independente de suas limitações. 
Com a avaliação, observou-se que por mais que o TPRA se mostre eficiente, alguns elementos se fazem essenciais para a ampla acessibilidade deste, como o piso tátil sobre a faixa elevada de pedestres, que se mostrou uma aplicação essencial para os usuários com deficiência visual, de acordo com as indicações feitas pelos voluntários nos passeios acompanhados.

Com a avaliação ficaram claros ganhos referentes à mobilidade dos usuários, refletidos no tempo de deslocamento, no conforto e na segurança; contudo, esse exemplo é muito pontual, e irrisório em termos de dimensão, dado o tamanho da UFPB; sendo sua ampliação essencial e urgente. Sugere-se ainda a diminuição da inclinação das rampas para variações entre $6 \%$ e $7 \%$, e deslocamento do piso tátil para um dos lados dos passeios, que só foram ajustes reconhecidos com ajuda dos usuários. As demais diretrizes propostas poderão servir como base para o planejamento de rotas acessíveis externas pela Universidade ou qualquer outro projeto similar.

O TPRA é o ponto de partida para uma UFPB amplamente acessível a todos; trata-se de um pequeno, mas significativo, trecho e importante meio de conscientização, que mostra como o espaço pode contribuir positivamente para a inclusão, facilitando a mobilidade dos usuários do Campus I.

\section{REFERÊNCIAS}

ASSOCIAÇÃO BRASILEIRA DE NORMAS TÉCNICAS. NBR 9050 - Acessibilidade a edificações, mobiliários, espaços e equipamentos urbanos. Rio de Janeiro: ABNT, 2004.

BRASIL. LEI No 10.098, DE 19 DE DEZEMBRO DE 2000. Estabelece normas gerais e critérios básicos para promoção da acessibilidade das pessoas portadoras de deficiência ou com mobilidade reduzida. 2000.

COSTA, Angelina D. L. Projeto Incluir 2011. UFPB para todos: eliminando barreiras. Ministério da Educação. Secretaria de Educação Superior. UFPB. João Pessoa, 2010.

DISCHINGER, Marta. Designing for all senses: Accessible spaces for visually impaired citizens. Tese (Doutorado) - Department of Space and Process, School of Architecture, Chalmers University of Technology. Göteborg, Suécia, 2000.

DISCHINGER, Marta; BINS ELY, Vera Helena Moro; PLARDI, Sonia Maria D. Groisman. Promovendo acessibilidade espacial nos edifícios públicos: Programa de Acessibilidade às Pessoas com Deficiência ou Mobilidade Reduzida nas Edificações de Uso Público. Florianópolis: MPSC, 2012. 161 p.: il., tabs., mapas.

RHEINGANTZ, Paulo Afonso; AZEVEDO, Giselle Arteiro; BRASILEIRO, Alice; ALCANTARA, Denise de; QUEIROZ, Mônica. Observando a qualidade do lugar: Procedimentos para a avaliação pós-ocupação. Coleção PROARQ. FAU/UFRJ. Rio de Janeiro/RJ, 2009. 